\title{
Hydrogels in acellular and cellular strategies for intervertebral disc regeneration
}

\author{
D. R. Pereira ${ }^{1,2 *}$, J. Silva-Correia ${ }^{1,2}$, J. M. Oliveira ${ }^{1,2}$ and R. L. Reis ${ }^{1,2}$ \\ ${ }^{1}$ 3B's Research Group - Biomaterials, Biodegradables and Biomimetics, Univ. Minho, Headquarters of the European Institute of Excellence \\ on Tissue Engineering and Regenerative Medicine, AvePark, S. Cláudio de Barco, 4806-909 Taipas, Guimarães, Portugal \\ ${ }^{2}$ ICVS/3B's - PT Government Associate Laboratory, Braga/Guimarães, Portugal
}

\begin{abstract}
Low back pain is an extremely common illness syndrome that causes patient suffering and disability and requires urgent solutions to improve the quality of life of these patients. Treatment options aimed to regenerate the intervertebral disc (IVD) are still under development. The cellular complexity of IVD, and consequently its fine regulatory system, makes it a challenge to the scientific community. Biomaterialsbased therapies are the most interesting solutions to date, whereby tissue engineering and regenerative medicine (TE\&RM) strategies are included. By using such strategies, i.e., combining biomaterials, cells, and biomolecules, the ultimate goal of reaching a complete integration between native and neo-tissue can be achieved. Hydrogels are promising materials for restoring IVD, mainly nucleus pulposus (NP). This study presents an overview of the use of hydrogels in acellular and cellular strategies for intervertebral disc regeneration. To better understand IVD and its functioning, this study will focus on several aspects: anatomy, pathophysiology, cellular and biomolecular performance, intrinsic healing processes, and current therapies. In addition, the application of hydrogels as NP substitutes will be addressed due to their similarities to NP mechanical properties and extracellular matrix. These hydrogels can be used in cellular strategies when combined with cells from different sources, or in acellular strategies by performing the functionalization of the hydrogels with biomolecules. In addition, a brief summary of therapies based on simple injection for primary biological repair will be examined. Finally, special emphasis will focus on reviewing original studies reporting on the use of autologous cells and biomolecules such as platelet-rich plasma and their potential clinical applications. Copyright (C) 2011 John Wiley \& Sons, Ltd.
\end{abstract}

Received 11 May 2011; Accepted 13 July 2011

Keywords acellular approach; biomaterials-based therapies; cellular approach; hydrogels, intervertebral disc regeneration; Gellan gum; tissue engineering; regenerative medicine

\section{Human spine and intervertebral disc (IVD)}

The human spine plays an important role in loading the structures where the internal organs are attached supporting the superior part of the body and transmitting loads between superior and inferior extremities (Pye et al., 2007). Body weight and muscle activity are the main factors responsible for such loads on the spine. The protection of

*Correspondence to: D. R. Pereira, 3B's Research Group Biomaterials, Biodegradables and Biomimetics, Univ. Minho, Headquarters of the European Institute of Excellence on Tissue Engineering and Regenerative Medicine, AvePark, S. Cláudio de Barco, 4806-909 Taipas, Guimarães, Portugal.

E-mail:drppimenta@gmail.com the nerves along this structure is provided from the brain to the periphery (arms and legs) (Bao et al., 1996; Kalson et al., 2004; Shankar et al., 2009). Occupying one-third of the spine height, the linked spine structure contains 24 intervertebral discs (IVDs) separating the bony vertebrae. Body motion is controlled by the IVDs in three distinct planes: lateral bending, axial rotation, and flexionextension (Twomey and Taylor, 1985; Roberts et al., 1989).

IVD is a fibrocartilaginous structure composed of three morphologically distinct regions (nucleus pulposus, annulus fibrosus, endplates) working together to absorb and disperse energy and transfer loads within the spine (Nerurkar et al., 2010; Lotz et al., 2002). Simultaneously, IVDs provide flexibility, enabling movements such as bending, flexion, and torsion. During heavy lifting activities, forces up to $17 \mathrm{kN}$ have been estimated in lumbar discs. All types of 
loads, mainly caused by torsion, can induce early degeneration in the disc (Cholewicki et al., 1991).

The central gelatinous core of the IVD, the nucleus pulposus (NP), is composed of $80 \%$ water during youth and progressively loses water content throughout the years (Coventry et al., 1945). Unlike other IVD regions, the NP develops from endoderm. In adulthood, the NP contains an amorphous matrix of proteoglycans (PGs) positioned in a network of randomly organized collagen (mainly type II) and elastin. The collagen crosslinking provides form and tensile strength to the NP, whereas the PGs (mainly aggrecan) maintain their viscoelastic properties, resistance to compression, and stiffness, since they sustain the osmotic pressure by which water enters and nutrient exchange occurs. The capacity to absorb and release water is related to the capacity to absorb shocks (Walker and Anderson, 2004; Singh et al., 2009; Woods et al., 2010). Two distinct regions are present in the annulus fibrosus (AF): the outer and the inner part, which have quite different characteristics. In the outer $\mathrm{AF}$, long and elastic collagen fibres lie parallel within each lamella orientated at $60^{\circ}$ to the vertical axis (Shankar et al., 2009). The outer AF arrangements provide resistance to tensile forces from body motions such as twisting and bending (Kalson et al., 2008). The inner AF is a transition zone between the highly organized outer $\mathrm{AF}$ and the highly hydrated NP. The characteristics of outer $\mathrm{AF}$ and $\mathrm{NP}$ are present in inner $\mathrm{AF}$, which then becomes a mixture of ECM components from both. The inner AF contains lower water content compared to NP. Moreover, inner AF is composed of layers that are more widely spaced than those of outer AF. Regarding mechanical properties, inner AF is more exposed to NP hydrostatic pressures than to outer AF tensile forces.

At the cellular level, NP and AF are morpho- and phenotypically distinct; therefore possessing dissimilar metabolic processes. IVD is populated by different cell phenotypes that are present in different cell numbers. NP is composed of rounded and chondrocyte-like cells at a density of $5 \times 10^{3}$ cells $/ \mathrm{mm}^{3}$, whereas AF contains $9 \times 10^{3}$ cells $/ \mathrm{mm}^{3}$ and possesses an elongated fibroblast like morphology (Eyre et al., 2002; Roughley, 2004; Roberts et al., 2006a, 2006b; Kalson et al., 2008). The two cartilage endplates act as a morphological and functional junction zone occupying $90 \%$ of the interface between the IVD and the vertebrae. These structures are composed mainly of hyaline cartilage similar to articular cartilage. The endplates serve as the main route for metabolites exchange due to their dense capillary network. The cells that populate these structures show a fibroblast like morphology (Weishaupt et al., 2001; Roberts et al., 2006a, 2006b; Woods et al., 2010).

\subsection{Biochemistry of the IVD}

The cellular metabolism of IVDs greatly depends on the finely balanced equilibrium assured by the action of biomolecules such as growth factors (GF), tumour necrosis factor (TNF), cytokines, and insulin like growth factors families (IGF). The extracellular matrix (ECM) of the distinct morphological IVD regions varies in composition. There are quite significant differences between NP and AF ECMs. The natural IVD balance is maintained by the action of different biomolecules such as cytokines and GF, which are responsible for controlling catabolic and anabolic processes. The process of intervertebral disc degeneration (IDD) leads to an increase in production of cytokines and matrix degrading enzymes (metalloproteinases; MMPs), leading to a predominance of catabolism over anabolism (Roberts et al., 2006a, 2006b; Clouet et al., 2009; Woods et al., 2010).

PGs, the glycosylated proteins that are strongly hydrophilic and commonly found in connective tissues are also abundant in NP. These proteins contribute to draw significant quantities of water into the disc. When PGs are present, the NP ECM expands to become a hydrogellike structure. Several types of PGs are present in the IVD. Aggrecan and versican are aggregated PGs largely responsible for NP hydration. Non-aggregating PGs such as decorin, biglycans, fibromodulin, lumican, and proglycan still do not have a well-defined function. The aggregated PGs aggrecan and versican are capable of binding glycosaminoglycans (GAGs) to the core, playing a role in cellular signaling. The mechanical properties of IVD depend directly on the number of GAG molecules linked to proteins, which in turn is directly related to the compression-resistance that IVD can load (Kalson et al., 2008). The protein Sox-9 (an essential regulatory gene for chondrocyte differentiation) is also expressed in healthy NP.

\subsection{Degenerative disc diseases; pathophysiology}

Mild microscopic IVD degenerative changes can be noticed with aging (Boos et al., 2002). In fact, it is the first body tissue to reveal signs of degeneration. IDD should be considered as a multi-factorial process dependent on genetic and environmental mechanisms. Studies on genetic predisposition to IDD, namely on cervical and lumbar regions, have suggested that there is a strong heritable component associated to this degenerative process (Sambrook et al., 1999). Most patients suffering from lower back pain (LBP) present different pathological conditions such as disc herniation, spinal stenosis, and myelopathy (Walker and Anderson, 2004; Kalson et al., 2008).

The healthy IVD structure is the largest avascular organ in the human body (Woods et al., 2010). As a result, the supply of essential nutrients and metabolites are dependent on the process of diffusion. Small blood vessels can be found in the outer region of the $\mathrm{AF}$ and sub-chondral bone but they are limited to $1-2 \mathrm{~mm}$ in depth. In a nonpathological condition, IVD has a diminished diffusion capacity that becomes even more reduced with aging and degenerative processes. The mechanism by which small molecules can penetrate into the disc is simple diffusion, 
which can compromise cell viability. However, cells are adapted to this environment, resulting in a low mitotic rate.

Another important issue related to the process of IDD is the anaerobic metabolism carried out by cells. In this respect, the relatively acidic $\mathrm{pH}$ from a non-pathological IVD (pH 6.9-7.2) decreases to $\mathrm{pH} 6.1$ under stress conditions (pathological condition). Under pathological conditions, inhibition of cell metabolism occurs, leading to matrix deterioration. These alterations, in combination with the poor innervations of the IVD (found only in the surface of the outer AF), make regeneration of this structure a real challenge (Buckwalter, 1995; Clouet et al., 2009).

The number of large aggregates of PGs present in the NP decreases throughout the years, contributing to a reduction of the water-binding capacity. Consequently, the desiccation of NP leads to the formation of clefts and tears in the AF. The asymmetric distribution of loads does not only affect the capacity of the disc to absorb and dissipate compressive loads but also diminishes the foramen dimensions, thereby leading to nerve compression (Boos et al., 2002; Hukins, 2005).

\subsection{Intrinsic healing process: current treatments}

LBP can be associated with IDD, since it is present in about $40 \%$ of patients (Luoma et al., 2000). A possible explanation for this is related to the proximity of surrounding muscles, joints or even the innervations of the outer AF. The self-repair capacity of IVD is confined only to the vascularized regions. ECM modifications lead to drastic effects in the overall IVD structure. This structure is aimed to compensate the abnormal distribution of forces when IDD occurs. Nevertheless, the IVD structure can occasionally be subjected to inappropriate stress, causing mechanical damage to the disc. Histological changes at the cellular level are manifested by an increase in cell proliferation and cell-cluster formation. Moreover, an increase in cell death (necrosis and apoptosis) can occur. The natural balance between anabolic and catabolic processes is strongly affected by degeneration (Trout et al., 1982; Gruber and Hanley, 1998; Johnson et al., 2001).

Randomized trials of therapeutic approaches are an option to relieve symptoms such as symptomatic medical treatments such as non-steroidal anti-inflammatory drugs (NSAIDs), paracetamol, and opioids that act as muscle relaxants. Last resources, including the use of antineuropathic drugs and invasive surgical methods are also a possibility. Nevertheless, these treatments have limited efficacy and cost-effectiveness (Deyo and Weinstein, 2001; Richardson et al., 2007; Kalson et al., 2008; Freimark and Czermak, 2009).

Current conservative practices for treating patients with acute or sub-acute LBP are directed towards removing the damaged tissue and/or stabilizing the resultant instability by surgery. The most common spinal surgery intervention is neurological decompression by discectomy, a procedure where the NP that is causing pain by stressing the spinal cord or radiating nerves is removed (Yeung and Yeung, 2007). Consequently, the disc height cannot be restored and the capacity to bear loads is dramatically reduced, thereby affecting the biomechanics of the IVD. Another surgical intervention commonly performed is bone fusion, wherein adjacent vertebrae are fused. To promote the growth of new bone to connect both vertebrae, bone grafting is usually performed. Recently, the use of bone morphogenetic protein 2 (BMP-2) in humans to promote the anterior lumbar inter-body fusion has been approved by the Food and Drug Administration (FDA) (Masuda, 2004). However, after bone fusion, flexibility was reduced and degenerative changes could be induced in adjacent vertebral bodies. Partial or total disc excision also presents serious contraindications and it has been performed followed by posterior replacement with artificial discs. There are no data reporting their long-term efficacy (Woods et al., 2010).Synthetic prostheses to replace IVD are now commercially available. The total IVD structure, or part of it, can be also removed to proceed with the insertion of allogeneic or autogeneic tissues. Both procedures present several difficulties and are thus not very feasible. In fact, when performing such types of interventions, height is reduced and water and PGs can also be lost. Finally yet importantly, there is the possibility of immunogenicity but low tissue availability could be an issue (Kalson et al., 2008; Kandel et al., 2008). Regenerative therapies can be divided into cell therapy, gene therapy, and tissue engineering. More recently, approaches using functionalized scaffolds showed to be a feasible therapy to restore the IVD (Hegewald et al., 2008).

\section{Biomaterials based therapies}

\subsection{Artificial disc: disc prosthesis}

Various devices to restore normal disc height and support loads have been extensively investigated. However, these devices lack some requirements to be successful in IVD restoration. Device migration, extrusion, and failure are some of the problems that can occur, thereby making these devices unsuitable. In addition, these types of devices have limited life-spans in vivo and require revision surgeries (Bao et al., 1996).

Total disc replacement could be performed using three different artificial disc options: metallic disc replacements, non-metallic materials, or a combination of both. Metallic devices take advantage of their high fatigue strength and of being capable to withstand loads up to 100 million constant amplitude cycles. As a result, the devices have a life-span of 40 years. However, strategies involving metallic replacements remain unable to replicate the complex motion of the disc. Metallic devices constructed from alloys (stainless steel, titanium, cobaltchromium) show high biocompatibility and are therefore being used in orthopaedic surgeries. However, the growth 
of fibrous tissue around the devices can compromise their application. Additionally, the friction between the device components can generate wear debris, leading to immune responses and even failure of the system (Boyd and Carter, 2006; Goins et al., 2005).

Non-metallic devices are composed of polymers and elastomers that possess mechanical similarities to the natural disc. The combination of metallic and non-metallic devices results in a sandwiched structure composed by metal-polymer-metal. Some strategies have focused on developing prosthesis to restore NP that easily resembles the IVD structure. However, in advanced stages of degeneration, those devices are not viable (Bao et al., 1996). Most prosthesis applications are created immediately after open surgery or percutaneous nucleotomy. The prosthetic disc nucleus (PDN) is one example of these devices and is comprised of two sections: the first is made up of a non-degradable hydrogel pellet (polyacrylamide) and the second, which surrounds the hydrogel, is a polymer mesh or jacket composed of polyethylene (Di Martino et al., 2005). Aquarelle ${ }^{\circledR}$ (Stryker ${ }^{\circledR}$ Orthopaedics, Mahwah, NJ, USA) is another example of an implant that is primarily composed of polyvinyl alcohol. Different kinds of prostheses have been reported such as Newcleus Spiral Implant, composed by a polymer with memory and NuCore ${ }^{\mathrm{TM}}$ (SpineWave Inc., Shelton, CT, USA), a copolymer of silk and elastin. The number of patents for injectable biomaterials aimed for NP restoration has increased in the last decade. In this respect, a wide range of biomaterials have been studied including chitosan, injectable synthetic polymers, recombinant bioelastic materials, cross-linkable silk elastin copolymer, and polyurethane-filled balloons (Boyd and Carter, 2006). Prosthetic discs are not seen as a good strategy to regenerate IVD since they lack the ability to remodel and sustain cyclical stress (Woods et al., 2010). Such devices require improvements in surgical techniques to avoid implant migration. Moreover, their efficacy requires extensive further research to be validated by clinical data (Goins et al., 2005).

\subsection{Polymeric-based Designs}

Many novel therapies have focused on restoring not only the IVD structure but also its functioning. Apart from focusing on pain suppression, new therapies should address IVD preservation, repair, reinforcement, and regeneration. The ultimate goal is to achieve mechanical stability and formation of neo-tissue resembling natural IVD over a long term. When considering the restoration of natural IVD function, it is important to define IVD stages of degeneration. Due to the huge number of loading cycles that the spine often bears, the potential substitute should be able to support significant physical loads. Regarding biocompatibility, the material should be able to degrade in balance with matrix synthesis without inducing acute immune responses or any deleterious cytotoxic effects. The sterilization process that both enables the preservation of original bioactivity and chemical composition and avoids bacteriological contamination appears to be a good procedure for hindering immune responses or even infections (Boyd and Carter, 2006). The best suited approaches may require a simple strategy or a more intricate design such as tissue engineering that can combine scaffolds, biomolecules, and cells, (Bron et al., 2009; Clouet et al., 2009). Advances in the field of tissue engineering and regenerative medicine (TE\&RM) have been targeting the replacement or repair of injured tissue by creating a structural and functional tissue mimicking the native one (Slaughter et al., 2009).

New insights on IVD substitute designs have been performed throughout the years. In the 60's, scientists (Nachemson and Evans, 1968) suggested the injection of vulcanized silicone into the degenerated disc. Later, Shneider et al. (Schneider and Oyen, 1974a, 1974b) proposed the use of silicone elastomer as an IVD substitute. Over 40 years, several IVD substitutes have been designed to restore IVD functioning. Currently, many substitutes have been produced by means of using synthetic, natural materials, and blends. Due to the many similarities between joint cartilage ECM and NP ECM, different scaffolds developed for joint regeneration could be an optimal choice in IVD tissue engineering (Clouet et al., 2009). Similarly, therapeutic strategies used in other types of cartilage such as articular cartilage and meniscus could also be considered for IVD regeneration. This is mainly due to the similarities of these tissues in terms of the harsh biologic and mechanical loading conditions (Setton et al., 2007).

Interestingly, some studies on cartilage repair could serve alternatively as guidelines in the design of new strategies for IVD regeneration. Elisseeff et al. (Elisseeff et al., 2000) encapsulated bovine and ovine chondrocytes in a poly(ethylene oxide)-dimethacrylate and poly(ethylene glycol) semi-interpenetrating network. The hydrogel constructs were obtained by photopolymerization and investigated for their mechanical properties and biological performance. Results showed that the chondrocytes were viable after 1 day of culturing and dispersed within the hydrogel. Over a period of 2 weeks, biochemical analysis revealed an increase in proteoglycans and collagen, leading to a functional ECM.

A 3D network to promote interaction between cells and ECM is crucial for the regulation of tissue morphogenesis. As reported elsewhere (Khetan et al., 2010), besides 3D environment remodeling ability, an appropriate material should be able to support cellular functions. Hyaluronic acid (HA) has been proposed as a material possessing such features but it has also been chemically modified for improving its biostability. In fact, HA hydrogels have been synthesized using multiple types of crosslinking. Using this strategy, encapsulated mesenchymal stem cells (MSCs) were able to spread in a controlled manner. The spatial control could be vital for developing complex microenvironments. As a result, the use of hydrogels in a clinical setting presents many advantages such as the possibility of being implanted using minimally invasive 
techniques. Besides, due to their gel-like behaviour, it is possible to predict an efficient filling of the complete defect area, which is an advantage from a materials integration point of view. An interesting study involving promising hydrogels has been reported by the Fan group (Fan et al., 2010). In their study, MSCs isolated from rabbit synovial tissue were encapsulated within Gellan gum hydrogels (GG). The constructs were cultured in vitro and proliferation and chondrocyte gene/protein expression were investigated over a period of 42 days. Results showed that the MSCs were viable and produced cartilaginous-like matrix (collagen and GAGs). Moreover, cells expressed chondrogenic markers such as collagen type II, Sox-9, biglycan, and aggrecan. Approved by the FDA, GG is a promising biomaterial when considering tissue-engineered cartilage. The pioneering studies performed by Oliveira et al (Oliveira et al., 2009a, 2009b; Oliveira et al., 2010) revealed that GG hydrogels have an adequate biological performance for finding a potential application in cartilage tissue engineering. As reported elsewhere (Oliveira et al., 2009a, 2009b), GG hydrogels not only allowed cell encapsulation but were shown to support human chondrocyte viability in vivo. Type II collagen and aggrecan were found to be expressed. In fact, a functional cartilage tissue was formed in nude mice after 4 weeks of subcutaneous implantation. Other interesting studies addressing IVD regeneration have been performed to evaluate the interaction of cell biomaterial in vitro. Unfortunately, few in vivo studies have been performed to date. Table 1 summarizes different approaches of cellular polymeric-based designs for IVD regeneration that show promise for future clinical application.

The three main components of IVD aimed at tissue regeneration are: 1) AF (Sato et al., 2003; Chang et al., 2007; Helen and Gough, 2007; Nerurkar et al., 2007; Shao and Hunter, 2007; Wan et al., 2007; Nerurkar et al., 2008; Wang et al., 2008; Nerurkar et al., 2009); 2) NP (Baer et al., 2001; Sakai et al., 2003; Seguin et al., 2004; Bertram et al., 2005; Wilke et al., 2006; Roughley et al., 2006; Cloyd et al., 2007; Chou et al., 2008; Halloran et al., 2008; Richardson et al., 2008; Vernengo et al., 2008; Bron et al., 2009; Chou et al., 2009; Sawamura et al., 2009; Calderon et al., 2010; Silva-Correia et al., 2010a; Silva-Correia et al., 2010b; Reza and Nicoll, 2010;); and 3) both NP and AF by means of using biphasic scaffolds (Mizuno et al., 2004; Hamilton et al., 2005; Mizuno et al., 2006; Nerurkar et al., 2008; Nesti et al., 2008). It has been proposed that for producing a tissue resembling natural IVD, total IVD replacement could be required. In this respect, strategies focused on the injection of cells and biomolecules alone or in combination have been proposed. However, when NP restoration is considered, it might not be possible to reverse all the IVD modifications (calcification observed in endplates), even when using approaches involving cell/scaffold constructs. The restoration of all AF functions is complex to achieve. Some specific requirements are required to validate the AF engineered scaffolds. The design should first not irritate or adhere to the perineurium; rather, it should have an anisotropic behaviour and secrete the native ECM while allowing the fixation of surrounding structures. It should also support direct mechanical strength. As a result, the lamellar and fibrocartilaginous framework of the AF will demand a highly organized and oriented tissue into distinct lamellae. The presence of collagen (mainly type I) in AF makes it resistant to tensile loads. Several strategies aimed at regenerating AF use different types of material, processing techniques, cells source, and phenotypes. Besides, it should be mentioned that the mechanical properties of such implants should resemble those of the native AF (Setton et al., 2007; Bron et al., 2009). This explains in part why strategies for $\mathrm{AF}$ regeneration are mainly focused on synthetic materials and their processing onto porous scaffolds and electrospun nets (Sato et al., 2003; Wan et al., 2007; Helen and Gough, 2007; Nerurkar et al., 2007; Nerurkar et al., 2008a, 2008b; Nerurkar et al., 2009; Chang et al., 2007; Wan et al., 2008).

Research within this field has been limited to date to fundamental in vitro and in vivo studies aimed to investigate cell attachment, proliferation, phenotypes, and ECM production in AF. For example, Sato et al. (Sato et al., 2003) demonstrated that AF cells isolated from rats retained a fibrocartilaginous phenotype and produced more ECM in 3D cultures compared to 2D (monolayer). To obtain scaffolds with unidirectional aligned fibres, Shao et al. (Shao et al., 2007) produced wet-spinned composite scaffolds of alginate and chitosan. The AF cells isolated from dogs were found to survive and proliferate. Moreover, both types of collagen (I and II) and aggrecan were found to be synthesized after 14 days. Similarly, Wan et al. (Wan et al., 2007) harvested AF cells from rats and in vitro studies revealed that these cells proliferated, leading to expression of type II collagen. The subcutaneous implantation of these constructs showed no immunogenic response. The degradation and tensile strength increased with a corresponding increased time of photopolymerization. Another study by Wan et al. (Wan et al., 2008) assessed the possible regeneration of outer and inner parts of AF using a biphasic construction. The outer AF was made up of bone matrix gelatine (BMG) and the inner $\mathrm{AF}$ was comprised of polycaprolactone triol malate (PPCLM). The incorporation of BMG in PPCLM improved the compressive strength of the construct. The outer AF structure was seeded with chondrocytes harvested from rabbits. After 4 weeks of culturing, the chondrocytes attached to the scaffolds, proliferated well, and migrated into the BMG. In both structures, production of type II collagen and aggrecan was observed over a period of 28 days.

Another study (Helen et al., 2007) carried out an in vitro study where scaffolds composed by poly DL-lactic acid (PDDLA) and Bioglass ${ }^{\circledR} / \mathrm{HDPE}$ (at different ratios) were processed as foams. The human cells seeded on these foams formed clusters attached to pores of PDDLA/30BG and PDLLA/5BG. The PDLLA/30BG foam showed the highest amount of GAGs formation, and in all cultures, the presence of collagen (mainly type I), was observed. Nerurkar and coworkers (2007; 2008; 2009) performed some studies involving electrospun 


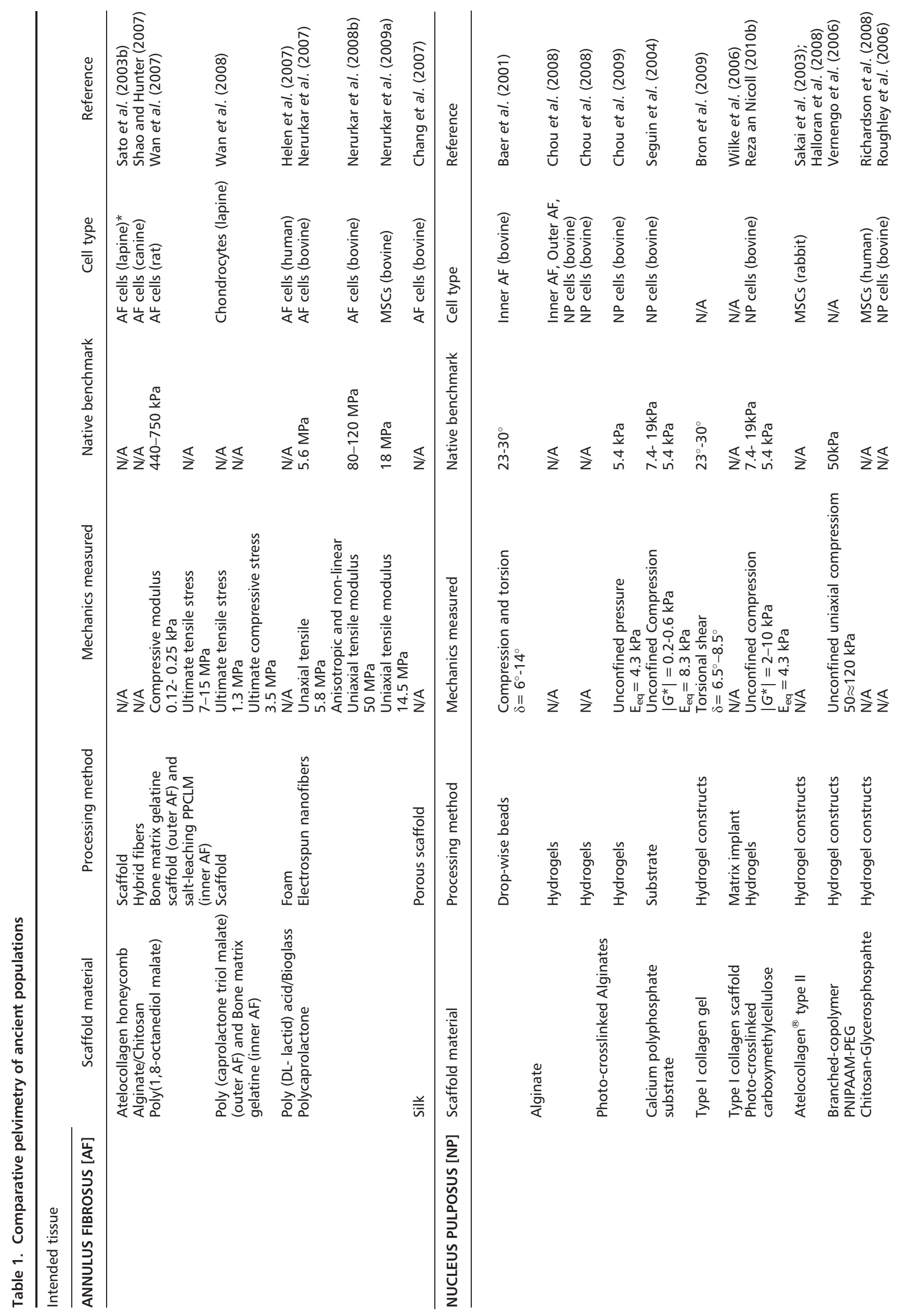




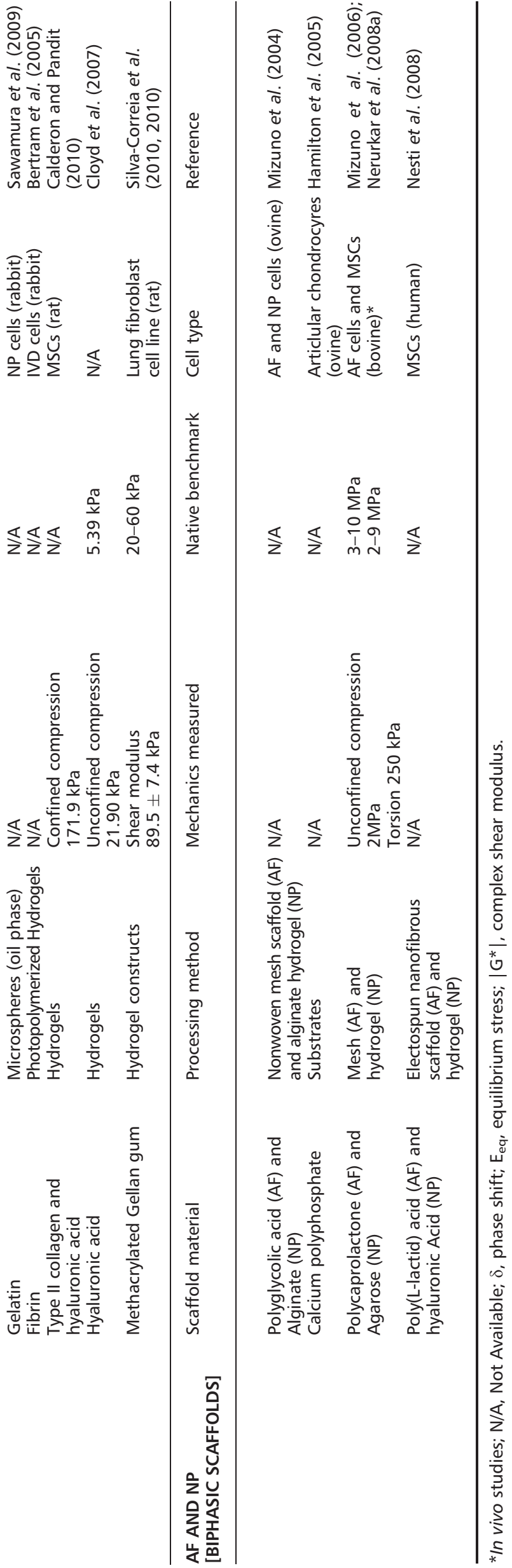

polycaprolactone (PCL). Different types of cells were seeded on the scaffolds but all of them supported cell alignment along the fibres. Biologically, GAGs and collagen increased during the culture period, showing that these scaffolds efficiently supported cellular functions.

\subsubsection{Hydrogels in cellular strategies for disc regeneration}

Nucleus pulposus (NP). Hydrogels have been attracting a great deal of attention in IVD regeneration due to the possibility of developing biomaterials that structurally resemble the ECM. A wide range of hydrogels have been studied for their wide physical and chemical properties. The hydrogel designs contemplate the performance of the implants in terms of structural integrity, biodegradability, biocompatibility, molecular response, solute transport and cellular behaviour, mechanical strength, and low viscosity.

Natural hydrogels are particularly appealing for such applications, mainly due to their inherent biocompatibility. However, synthetic hydrogels allow for large-scale production and offer consistent and highly tunable properties, which are important advantages. However, since most synthetic procedures involve harsh reagents, there is a need to ensure that contaminants and unreacted reagents are completely removed (Slaughter et al., 2009). This issue is extremely important to avoid possible cytotoxic and immunogenic effects.

The 3D network of hydrogels makes them the best option to allow the interaction of cells and ECM, leading to a dynamic tissue morphogenesis (Khetan et al., 2010). Hydrophilic polymers (co-, homo-, or macromers) are able to be crosslinked to improve their bio-stability in vitro and in vivo. The hydrogels are typically soft and elastic after crosslinking (Slaughter et al., 2009). These injectable biomaterials are most advantageous since they allow the incorporation of cells and biomolecules alone or in combination. The possibility of injection by a small puncture, which can reduce the surgical damage and allow good dispersion of cells and/or biomolecules within the material, makes hydrogels suitable substitutes for NP. In this respect, the NP substitutes should not only be able to completely fill the shape and size of the damage but also be well fixed in the NP space (Boyd and Carter, 2006). The amplification of the repair process can be enhanced through GF-, TNF-, or IGF-functionalization of the injectable materials. As a result, injectable and functionalized hydrogels that can be ionic and/or chemically crosslinked appear to be a promising alternative for restoring natural NP functions. Another challenge that has been addressed concerns the mechanical properties of NP, which is a quite soft tissue (5 $\mathrm{kPa}$ ) due to its unconfined compression (Nerurkar et al., 2010). In this respect, hydrogels are also very versatile and by varying the type of material, molecular weight, degree of crosslinking, chemistry, and functionalization, it could be possible to mimic the mechanical properties of the native tissue. 
Several strategies have been examined to replace NP healthy functions. These are summarized in Table 1 (Baer et al., 2001; Sakai et al., 2003; Seguin et al., 2004; Bertram et al., 2005; Wilke et al., 2006; Roughley et al., 2006; Cloyd et al., 2007; Chou et al., 2008; Halloran et al., 2008; Richardson et al., 2008; Vernengo et al., 2008; Bron et al., 2009; Chou et al., 2009; Sawamura et al., 2009; Calderon et al., 2010; Silva-Correia et al., 2010; Silva-Correia et al., 2010; Reza and Nicoll, 2010;).

Similarly, Baer (Baer et al., 2001) investigated the mechanical behaviour of NP in terms of compressive and torsional shears. Alginate hydrogels cultured with porcine cells isolated from inner AF were maintained for 16 weeks in vitro. Posterior assessments revealed the maintenance of NP-like phenotype. Although a decrease of shear stress was observed, the values remained in the same order of magnitude compared to native tissue. Another study performed by Bron et al. (Bron et al., 2009) demonstrated that type I collagen gels presented a lower phase angle compared to native tissue but showed quite favourable results concerning shear modulus. Reza and Nicoll (Reza and Nicoll, 2010) studied different methods to obtain photocrosslinked hydrogels by modifying carboxymethylcellulose with methacrylate groups. Bovine NP cellencapsulated hydrogels were viable at 7 days of culturing. Moreover, the developed hydrogels showed good values to elastic modulus. Histological assessments showed that cells possessed a round morphology and production of proteoglycans was observed after 14 days of culturing.

In vivo effects of platelet-rich plasma-impregnated gelatine hydrogels microspheres were developed to find applications for the treatment of IDD. Chitosan has been proposed as a suitable cell-based scaffold (Roughley et al., 2006). In that study, NP cells were encapsulated in different formulations of chitosan-glycerophosphate gels. In vitro results showed proteoglycans (PGs) production by NP cells. These were found to be entrapped into the hydrogels rather than released into the culture medium. Their studies also demonstrated that water content in such constructs was preserved. The production of PGs core proteins assessed by mRNA synthesis was increased compared to other constructs. Similarly, type II collagen production also increased. However, cells in the proliferating state were not found in NP and inner AF. A significant decrease in apoptotic cells in NP was observed. A study by Calderon et al. (Calderon et al., 2010) proposed different polymers to regenerate NP. In that study, two types of materials, type I collagen and HA, were seeded with MSCs. The hydrogels demonstrated to be stable in vitro. The level of crosslinking was found to have a significant influence on both swelling properties and cellular proliferation. They also evaluated the differentiation of MSCs into chondrogenic lineage. The current study group (Silva-Correia et al., 2010a, 2010b) has proposed the use of novel chemically modified Gellan gum hydrogels with the hope of finding applications for NP regeneration. The methacrylation of Gellan gum (GG-MA) allowed the synthesis of both ionic- and photo-crosslinkable hydrogels for in situ gelification. Moreover, the ability of these hydrogels to be photo-crosslinked by UV light lead to the production of hydrogels with improved mechanical properties that ultimately could mimic NP. This in vitro study showed that the hydrogels (GG-MA) were non-cytotoxic over L929 cells. Since the chemical modification GG improved the physicochemical and biological versatilities of the hydrogels, the produced GG-MA appeared as a suitable biomaterial to be used in NP regeneration (Cloyd et al., 2006).

Recently, this study group (Pereira et al., 2011) proposed a substitute to regenerate NP by means of using Gellan gum hydrogel matrices with cell-loaded microparticles (MPs). Two forms of Gellan gum (High and Low acyl) were combined in different ratios and processed as matrices and MPs. The matrices were reinforced with MPs possessing the same formulation. Mechanically, the formulation of 25\% HAGG: 75\% LAGG incorporated with MPs at $50 \mathrm{mg} / \mathrm{ml}$ showed the best mechanical performance compared to native NP. All hydrogel formulations were tested in vitro to screen for possible cytotoxicity. The cell culture studies revealed that the hydrogels did not have a cytotoxic effect over L929 cells. Moreover, the cell-loaded MPs were efficiently produced and L929 cells remained viable over a period of 72 hours.

Biphasic scaffolds for $\boldsymbol{A F}$ and NP. To restore IVD, therapeutic approaches should address not only the anatomic aspects and mechanical behaviour of the tissue, but primarily ensure that the natural functions of IVD are recovered. The complex and heterogeneous IVD needs to be well defined and should be the main goal when tissue engineering this tissue. As a result, strategies addressing the different components of IVD structure, NP, and $\mathrm{AF}$, could be required to restore IVD functions. As shown in Table 1, few studies have shown the efficacy of synthetic and natural polymers to regenerate AF and NP (Mizuno et al., 2004; Hamilton et al., 2005; Mizuno et al., 2006; Nerurkar et al., 2008; Nesti et al., 2008). However, a study performed by Mizuno et al. (Mizuno et al., 2004) revealed the efficacy of an integrated biphasic composite for $\mathrm{AF}$ and NP regeneration. The polymers used were polyglycolic acid seeded with AF cells and alginate scaffolds cultured with NP cells. The in vivo study was performed in rats for 12 weeks. Despite the innovative character of the study, results showed that the implant only allowed the synthesis of half the amount of PGs and collagen compared to native tissue. In another integrative tissue engineering study, Hamilton et al. (2005) developed a calcified tissue cartilaginous endplate NP. The first approach was to generate a hyaline cartilage tissue layer seeded with NP cells on calcium polyphosphates substrates. The NP cells were able to synthesize the PGs that are found in natural discs but did not produce collagen. More research is required to integrate all IVD structures.

Other studies (Mizuno et al., 2006; Nerurkar et al., 2008) developed an interesting strategy to replicate the microstructural organization of AF by using scaffolds made of aligned PCL nanofibers. The centre of the PCL scaffold was filled with agarose to resemble NP. The compressive properties of agarose increased by reinforcement with the 
multilamellar PCL nanofibers. The frameworks resembling the natural ones allowed cells to adopt opposing orientations of $\pm 30^{\circ}$. Consequently, a deposition of collagen into multilamellar angle-ply organization was observed. Similarly, a study performed by Nesti (Nesti et al., 2008) consisted of coupling HA hydrogel with electrospun nanofibers of poly(L-lactic) acid (PLLA). The HA was used to encapsulate MSCs that were injected at the centre of the non-aligned nanofibrous mesh. The nanofibrous mesh was also seeded with MSCs to produce cells possessing a different phenotype. In the AF region, cells developed a fibroblastic like phenotype. A chondrogenic phenotype was observed in cells encapsulated in the HA hydrogel. As a result, that study reported the production of disc-like tissue by means of using MSCs seeded in biphasic scaffolds.

Cell Source. The cells that were investigated to engineer tissues can be obtained from different sources and have different origins, namely, human and animal (canine, ovine, bovine, rabbit). The lack of healthy human disc cells impairs their use in tissue engineering strategies. Some studies (Roberts et al., 2006; Gruber et al., 2007; Le Maitre et al., 2007) reported a high degree of senescence of the cells when herniated discs were the source of the cells. Cells from discs showing degeneration may not be an optimal source of cells for tissue engineering strategies (Gruber et al., 1998). The isolation of cells from healthy human IVDs raises important issues that should be taken in account: the natural environment of cells is significantly changed after isolation and the removal of tissues to isolate healthy cells can lead to IDD (Woods et al., 2010). To deal with this drawback, cells recovered from healthy IVDs of small animals show promise as a feasible alternative. To obtain a sufficient number of cells for tissue engineering and regenerative medicine (TE\&RM) applications, these cells need to be first expanded in vitro for several weeks.

Currently, notochordal cells and MSCs have been well investigated for their regenerative potential. Studies involving their use in the regeneration of osteoarticular tissue encourage researchers to explore similar cellular strategies for IVD regeneration. These cells can differentiate into different phenotypes, namely NP cells (Vernengo et al., 2008) and chondrocytes (Merceron et al., 2008; Vinatier et al., 2009). Richardson et al. (Richardson et al., 2006) showed that co-cultures of normal human NP and normal human MSCs with and without cell-cell interaction resulted in MSCs with an NP-like phenotype. It was shown by an increase in aggrecan and type II collagen genes. Studies of bone marrow and adipose tissue have also been performed. Vadala et al. (Vadala et al., 2008) performed a study with MSCs co-cultured with NP cells. The study revealed an altered gene profile expression and the up-regulation of ECM synthesis.

Besides MSCs, nothocordal cells have been proposed as a good choice for use in TE\&RM. These types of cells are not produced in adult human IVDs; however some animals express these cells over their life time. Aguiar et al. (Aguiar et al., 1999) carried out a study involving co-cultures of nothocordal cells with NP cells. The in vitro studies showed an increase in PG synthesis. However, when using these cells, the risk of tumour growth could not be discarded in both cases and its screening should be well assessed (Sakai et al., 2008).

To efficiently regenerate injured tissues, the cells seeded into the materials should demonstrate characteristics similar to those found in normal tissues. As a result, cells cultured in vitro often require the presence of specific morphogenetic factors. The characteristic phenotype of each cell type can be maintained by mean of culturing in a 3D environment (Benya and Shaffer, 1982; Vinatier et al., 2005). The vast amount of research efforts on cartilage tissue engineering will certainly improve knowledge in this field and hopefully will be applied in IVD TE\&RM (Clouet et al., 2009). Chou et al. (Chou et al., 2006) reported the negative effect of cell cultures of inner and outer AF in 2D. That study showed that cells lost their phenotype up to passage two. In later stages, both types of cells became indistinguishable. Reza et al. (Reza and Nicoll, 2008) showed that cells from inner and outer AF were able to express collagen type II when seeded in poly-glycolic acid (PGA) scaffolds and cultured under hydrostatic pressure. The scaffolds seeded with outer AF cells expressed a more pronounced and organized ECM. However, it was reported that cells were able to express mainly collagen type I in vivo (Bron et al., 2009). As a result, further studies are required to develop adequate TE\&RM strategies for obtaining the production of a native-like ECM.

\subsubsection{Hydrogels in acellular strategies for disc regeneration}

Cell-free scaffolds have also been investigated for their potential as IVD substitutes. The advantages of these substitutes are mainly associated with mechanically stability and present less shipping constraints and longer shelf life compared to cell-based scaffolds (Woods et al., 2010). As reported by Abbushi et al. (2008) and Endres et al. (2010), implantation of PGA-HA scaffolds, which have been shown to be suitable for proteoglycans-rich tissues, induces the regeneration of NP. The migration of cells into the defect area is responsible for the increase of the amount of PGs within a period of 12 months. To produce cell-free scaffolds capable to restore the IVD, Waldman et al. (2002) and Seguin et al. (2004) showed that calcium phosphates ould be used as substrates to engineer NP and endplates in vitro. The success of this strategy relies on the similarity to native tissue; once the PGs are being synthesized and the biomechanical properties closely resemble the natural ones.

Biomolecules to functionalize hydrogels. Scaffold performance can be improved by functionalization of the biomaterial. The capacity of polymers to bind or be linked to biomolecules has been attracting a great deal of attention in IVD regenerative strategies. To recruit and protect growth factors such as bone morphogenetic proteins (BMPs), basic fibroblastic growth factors (bFGFs) and vascular endothelial growth factors (VEGFs), heparin 
functionalization has been explored by several authors (Nie and Wang, 2007; Joung et al., 2008). Heparin functionalization could be a good strategy due to its ability to bind to biomolecules. In this way, a wide range of methods have been developed towards functionalized scaffolds with heparin (Fugita et al., 2004). Hydrogel constructs functionalized with heparin and fluvastin have also been proposed for bone repair. Benoit (Benoit et al., 2007) showed that the developed scaffolds were able to promote osteogenic differentiation of human MSCs. Similarly, Edlund et al. (2008) reported that BMP-2 loaded in heparin functionalized polymers improved adhesion and proliferation of murine MSCs. Another study (Fujita et al., 2004) showed that biologically active FGF-2 was stimulated by chitosan/ periodate-oxidized $\left(\mathrm{IO}_{4}\right)$ heparin hydrogels. The studies reported by Fujita and Edlund (Fujita et al., 2004; Edlund et al., 2008) showed that functionalized materials are effective in promoting IVD regeneration. Covalent linking of heparin to scaffolds has been described as the most attractive method to functionalize materials (Yang and Li, 2009). Nevertheless, a novel approach to design scaffolds by heparin carrying microcapsules was reported by $\mathrm{Li}$ et al. (2009). The microcapsules were grafted to the material, which ensured minimal loss of bioactivity and kept the heparin molecules intact.

Chang et al. (2007) developed a strategy to improve cell attachment on the silk porous scaffolds by chemical bonding to the RGD, an integrin binding motif. The study showed that improvement of cell adhesion was not achieved but that collagen type II and aggrecan production increased. However, the increase of collagen type II and aggrecan observed was not suitable for the regeneration of AF since collagen type II is not able to form or bundle fibrillated structures. Therefore, the use of biomolecules such as decorin or small PGs could be addressed when functionalization of biomaterials is considered. These biomolecules are known to be capable to bind TGF- $\beta$ and have increasingly been used in fundamental studies (Macri et al., 2007).

\section{Direct injected-based therapies}

\subsection{Cell therapy}

The continuous investigation of IVD biology and its degenerative cascades has created novel concepts for developing functional solutions at a cellular level (Woods et al., 2010). Frequently, IDD appears at an early age, especially during the second decade of life. The abnormal cell-mediated response leads to injuries at the cellular level (Woods et al., 2010). As a result, it has been proposed to use of cellular strategies to efficiently regenerate IVD. The reinsertion of autologous cells can limit the application of cell therapies. Human IVD lacks in nothocordal cells and differentiated cells harvested from degenerated IVDs show an altered phenotype impairing their use in clinics. Moreover, surgical procedures to harvest cells can induce degeneration in healthy discs. Degenerated discs show cells possessing different phenotypes due to altered biochemical processes, which lead to increased rates of senescent cells. The clinical application of such cells can induce a degenerative cascade of the IVD. The regeneration of the IVD by reinsertion of allogeneic cells poses the risks of immune rejection, allergy, or disease transmission. Despite being non-vascular and non-innervated, IVD pathological conditions are associated with an increase in neovascularization and innervations. Stem cells lack the specific markers responsible for determining the cell lineage (Woods et al., 2010). As a result, stem cells could be excellent candidates to repair IVD when considering the use of cellular approaches. In a study reported by Sobajima et al. (Sobajima et al., 2008), human mesenchymal stem cells (hMSCs) were co-cultured with human nucleus pulposus cells (hNPCs) to assess the feasibility of stem cells in restoring IVD. The transplanted stem cells showed excellent viability and migration through different IVD structures and differentiated in several phenotypes. However, some specific markers were not expressed in the used cell type. The presence of molecules such as aggrecan, collagen type II, and SOX-9 allows us to distinguish the IVD cells. However, these markers are non-specific and are also used to identify articular chondrocytes, for example (Risbud et al., 2004).

\subsection{Biomolecules therapy}

One approach to stimulate IVD regeneration is based on the direct injection of biomolecules acting as activators for ECM production. IVD cells are differently influenced by several growth factors and enzymes, which can be injected as pure protein solutions or combined with matrices that allow their controlled release. Most studies involving the use of BMPs in IVD were aimed at stimulating ECM production (Zhang et al., 2007). In the study reported by Zhang et al. (Zhang et al., 2007), AF cells were stimulated with different BMPs and by Sox-9 transfection studies. The collagen synthesis was increased by over-expression of such molecules. Interestingly, another study (Takegami et al., 2005) reported the repair of ECM by stimulation of AF cells with OP-1 (also known as BMP-7). Masuda et al. study (Masuda et al., 2003) showed a significant increase in total DNA, PG synthesis, and collagen content by continuous stimulation of AF cells with BMP-7. In addition, the study was able to establish the best performance of BMP-7 on NP compared to AF results. Currently, BMP-7 is widely used in studies related to bone and cartilage tissue engineering. The chondrocyte differentiation results in a stimulation of matrix production, mainly PGs and collagen type II (Kong et al., 2008). BMP-2 has been shown to exert potent effects both in articular chondrocyte ingrowth capacity and anabolic processes. Although, some in vivo studies showed an increase of IVD degeneration in rats treated with BMPs (Huang et al., 2007). 
Recently, some studies proposed the use of platelet-rich plasma (PRP) to stimulate cell proliferation and ECM metabolism of the IVD cells. The activated platelets were able to release multiple growth factors directly involved in regulation of cell proliferation, differentiation, and morphogenesis. Akeda et al. (Akeda et al., 2006) showed the effect of using PRP in stimulating cell proliferation and ECM metabolism. PRP cultured in alginate beads up-regulated PGs and collagen syntheses, while accumulated PG amounts were higher compared to platelet-poor plasma. In other studies, Nagae et al. (Nagae et al., 2007) and Sawamura et al. (Sawamura et al., 2009) investigated the in vivo effect of PRP-impregnated gelatin hydrogel microspheres (PRP-GHM). Both studies presented a significant suppression of the progression of IVD degeneration. Similarly, Nagae et al. (Nagae et al. 2007) proposed a different strategy in which PRP was injected directly into the NP of degenerated IVD, instead of being impregnated into gelatin hydrogel microspheres. The progressive degeneration of the IVD was suppressed over 8 weeks of PRP administration. Sawamura et al. (Sawamura et al., 2009) reported an increase of IVD height after treatment with PRP-GHM. The presence of water was also preserved in PRP-GHM administration. Moreover, the mRNA expression of PGs core protein and type II collagen increased after treatment with PRP-GHM. Although no proliferating cells were found in the IVDs treated with PRP-GHM, there was a decrease in the number of apoptotic cells in the NP. However, the lack of studies in animals or humans does not make this approach feasible yet. The regeneration of IVD by direct injection of biomolecules is limited since it is only of short-term action. This option could be feasible only for mild or moderate degenerated discs (Freimark and Czermak, 2009).

\subsection{Gene therapy}

Gene expression profiles can be changed by means of gene therapy. To envisage a long-term stimulation of the disc, activators can be introduced into the IVD cells genome. Two main methods are commonly used (Kalson et al., 2008). The in vivo method uses exogenous therapeutic genes to target cells throughout injectable vectors. In the ex vivo method, the targeted cells are removed and expansion of the cells is performed in vitro and only then are re-implanted. The second method is preferred and it involves a virus or a non-viral carrier that aims to serve as vehicle to integrate the gene of the activator (Freimark and Czermak, 2009). However, adenoviruses can induce strong immune reactions in vivo. To diminish such a response, it has been proposed to use adeno-associated viral vectors. Such strategies have shown positive results. The synergistic effect of using adeno-mediated therapies might be helpful in restoring the IVD functions.

An experiment carried out for 6 weeks in a IVDs mouse model (Nishida et al.,1999) demonstrated that gene transfection of TGF- $\beta$ had a two-fold increase in PG synthesis. A considerable increase of PGs and TGF- $\beta$ were present during the experimental period. The successful integration of genes of BMP-2 and IGF- 1 by adenovirus vector has also been reported in vitro (Wallach et al., 2003; Moon et al., 2008). Both studies revealed an increase in the synthesis of intradiscal PGs in a dosedependent manner. Nevertheless, the paucity of studies focusing on the unlimited and uncontrolled release of biomolecules makes gene therapy approaches questionable (Freimark and Czermak, 2009). Many issues are raised: namely, the choice of the vector, method and timing of delivery, course of action, safety of gene transfer, and therapeutic gene biology. An interesting study (Grunhagen et al., 2006) reported a contraindication of this therapy, suggesting a potential degeneration effect due to the increase of cellular metabolism in a harsh environment. However, gene therapy has been proposed as an alternative to large surgical interventions (Woods et al., 2010).

\section{Future outlooks}

Over the past two decades, significant efforts have been made to develop novel regenerative strategies targeted to IVD. The important socio-economical impacts of LBP in society became a serious problem with large annual expenses. Human disability and suffering are uncomfortable conditions and current treatments cannot solve these problematic on a long-term basis. The stage of IVD damage should be accurately assessed in order to design the most suitable substitute(s). Many problems are continuously emerging while strategies to restore/regenerate IDD are under development. The pathological state as cause of degeneration is not well defined. A considerable knowledge achieved in cartilage tissue repair is nowadays used for IVD restoration. However, the high complexity and heterogeneity of IVD require an increase in the fundamental knowledge to understand all processes involved in IVD degeneration. To be feasible, an IVD regenerative strategy should require integration among native tissues and generation of functional neo-tissue. Therapies using cells, biomaterials, biomolecules, or gene therapy by direct injection are performed as standalone therapies. Nevertheless, the short-term success and the unclear long-term consequences become a pitfall. Meanwhile, such strategies are used to restore a single tissue. Novel approaches are being studied focusing on restoration of two dissimilar tissues, the AF and NP. All approaches involve the use of cells/biomolecules/genes alone or combined with biomaterials, mainly hydrogels. Significant research should be conducted to clarify both common and specific cellular responses in human IVD. Autologous cells and growth factors have shown great promise for developing a new generation of biological-based therapies. Mimicking the natural environment outside the body can be a huge challenge in some fields of engineering, especially those focusing on replicating the in vivo mechanical stimuli. 
Regenerative therapies can only succeed if guided by a clear vision of their future clinical applications. To efficiently translate TE\&RM strategies into clinical practice, scientists should perform in vivo studies using an appropriate animal model. Animal IDD can occur spontaneously or in an induced way; but by proceeding with the latter, the experiments could be compromised. When animal IVD is punctured to induce IDD, the pathological condition can rise up intensively after the procedure. Different species exhibit different biochemistry and biological behaviours. The unclear knowledge about such features in animals can result in erroneous conclusions. Inferring the data obtained in animals to humans is also a difficult task. The most used animals in the in vitro studies involve rat, rabbit, and sheep models. Similarly to humans, rabbits lose their nothocordal cells and due to their anatomic position, resemblance makes them a suitable model for in vivo studies. Despite these pitfalls, TE\&RM provides hope to IVD and a consensus on which strategies could be developed to treat LBP might not be too far.

\section{Acknowledgements}

The authors would like to acknowledge the Portuguese Foundation for Science and Technology (FCT) through the POCTI and FEDER programs, including Project ProteoLight (Grant No. PTDC/FIS/68517/2006) for the provided funds. This work was also carried out under the scope of European Unionfunded Collaborative Project Disc Regeneration (Grant No. NMP3-LA-2008-213904).

\section{References}

Abbushi A, Endres M, Cabraja M, et al. 2008; Regeneration of intervertebral disc tissue by resorbable cell-free polyglycolic acidbased implants in a rabbit model of disc degeneration. Spine 33: 1527-1532.

Aguiar DJ, Johnson SL, Oegema TR. 1999; Notochordal cells interact with nucleus pulposus cells: regulation of proteoglycan synthesis. Exp. Cell Res. 246: 129-137.

Akeda K, An HS, Pichika R, et al. 2006; Platelet-rich plasma (PRP) stimulates the extracellular matrix metabolism of porcine nucleus pulposus and anulus fibrosus cells cultured in alginate beads. Spine 31: 959-966.

Boos N, Weissbach S, Rohrbach $\mathrm{H}$, et al. 2002; Classification of age-related changes in Lumbar intervertebral discs: 2002 Volvo Award in basic science. Spine 27: 2631-2644.

Buckwalter JA. 1995; Aging and degeneration of the human intervertebral disc. Spine 20: 1307-1314.

Boyd L, Carter A. 2006; Injectable biomaterials and vertebral endplate treatment for repair and regeneration of the intervertebral disc. Eur. Spine J. 15: 414-421.

Baer AE, Wang JY, Kraus VB, et al. 2001; Collagen gene expression and mechanical properties of intervertebral disc cellalginate cultures. J. Orthop. Res. 19: 2-10.

Bao Q-B, McCullen GM, Higham PA, et al. 1996; The artificial disc: theory, design and materials. Biomaterials 17: 1157-1167.

Bron JL, Koenderink GH, Everts V, et al. 2009; Rheological characterization of the nucleus pulposus and dense collagen scaf folds intended for functional replacement. J. Orthop. Res. 27: 620-626.

Bertram H, Kroeber M, Wang H, et al. 2005; Matrix-assisted cell transfer for intervertebral disc cell therapy. Biochem. Biophys. Res. Commun. 331: 1185-1192.

Benya PD, Shaffer JD. 1982; Dedifferentiated chondrocytes reexpress the differentiated collagen phenotype when cultured in agarose gels. Cell 30: 215-224.

Benoit DSW, Collins SD, Anseth KS. 2007; Multifunctional hydrogels that promote osteogenic human mesenchymal stem cell differentiation through stimulation and sequestering of bone morphogenic protein 2. Adv Funct Mater 17: 2085-2093. Cholewicki J, MCGill SM, Norman RW. 1991; Lumbar spine loads during the lifting of extremely heavy weights. Med. Sci. Sports Exerc. 23: 1179-1186.

Coventry MB, Ghormley RK, Kernohan JW. 1945; The intervertebral disc: micrscopic anatomy and pathology: Part I. Anatomy, Development, and Physiology. J Bone Joint Surg Am 27: 105-112.

Clouet J, Vinatier C, Merceron C, et al. 2009 The intervertebral disc: from pathophysiology to tissue engineering. Joint Bone Spine 76: 614-618.

Calderon L, Collin E, Velasco-Bayon D, et al. 2010; Type II collagen-hyaluronan hydrogel-a step towards a scaffold for intervertebral disc tissue engineering. Eur. Cell. Mater. 20: 134-148.

Cloyd J, Malhotra N, Weng L, et al. 2007; Material properties in unconfined compression of human nucleus pulposus, injectable hyaluronic acid-based hydrogels and tissue engineering scaffolds. Eur. Spine J. 16: 1892-1898.

Chou AI, Reza AT, Nicoll SB. 2008; Distinct intervertebral disc cell populations adopt similar phenotypes in three-dimensional culture. Tissue Eng. Part A 14: 2079-2087.

Chang G, Kim HJ, Kaplan D, et al. 2007; Porous silk scaffolds can be used for tissue engineering annulus fibrosus. Eur. Spine $J$. 16: 1848-1857.

Chou AI, Nicoll SB. 2009; Characterization of photocrosslinked alginate hydrogels for nucleus pulposus cell encapsulation. $J$. Biomed. Mater. Res. A 91: 187-194.

Chou AI, Bansal A, Miller GJ, et al. 2006; The effect of serial monolayer passaging on the collagen expression profile of outer and inner anulus fibrosus cells. Spine 31: 1875-1881.

Deyo RA, Weinstein JN. 2001; Low Back Pain. N. Engl. J. Med. 344: 363-370.

Di Martino A, Vaccaro AR, Lee JY, et al. 2005; Nucleus pulposus replacement: basic science and indications for clinical use. Spine 30: 16-22.

Eyre DR, Matsui Y, Wu J-J. 2002; Collagen polymorphisms of the intervertebral disc. Biochem. Soc. Trans. 30: 844-848.
Elisseeff J, McIntosh W, Anseth $\mathrm{K}$, et al. 2000; Photoencapsulation of chondrocytes in poly(ethylene oxide)-based semiinterpenetrating networks. J. Biomed. Mater. Res. 51: 164-171.

Edlund U, Danmark S, Albertsson AC. 2008; A strategy for the covalent functionalization of resorbable polymers with heparin and osteoinductive growth factor. Biomacromolecules 9: 901-905.

Endres M, Abbushi A, Thomale UW, et al. 2010; Intervertebral disc regeneration after implantation of a cell-free bioresorbable implant in a rabbit disc degeneration model. Biomaterials 31: 5836-5841.

Freimark D, Czermak P. 2009; Cell-based regeneration of intervertebral disc defects: review and concepts. Int. J. Artif. Organs 32: 197-203.

Fan J, Gong Y, Ren L, et al. 2010; In vitro engineered cartilage using synoviumderived mesenchymal stem cells with injectable gellan hydrogels. Acta Biomater. 6: 1178-1185.

Fujita M, Ishihara M, Simizu M, et al. 2004; Vascularization in vivo caused by the controlled release of fibroblast growth factor-2 from an injectable chitosan/nonanticoagulant heparin hydrogel. Biomaterials 25: 699-706.

Gruber HE, Hanley ENJ. 1998; Analysis of aging and degeneration of the human intervertebral disc: comparison of surgical specimens with normal controls. Spine 23: 751-757.

Goins ML, Wimberley DW, Yuan PS, et al. 2005; Nucleus pulposus replacement: an emerging technology. Spine J. 5: 317-324.

Gruber HE, Ingram JA, Norton $\mathrm{HJ}$, et al. 2007; Senescence in cells of the aging and degenerating intervertebral disc: Immunolocalization of senescence-associated galactosidase in human and sand rat discs. Spine 32: 321-327.

Grunhagen T, Wilde G, Soukane DM, et al. 2006; Nutrient Supply and Intervertebral Disc Metabolism. J Bone Joint Surg Am 88: 30-35.

Hukins DWL. 2005; Tissue engineering: A live disc. Nat. Mater. 4: 881-882. 
Huang KY, Yan JJ, Hsieh CC, et al. 2007; The in vivo biological effects of intradiscal recombinant human bone morphogenetic protein-2 on the injured intervertebral disc: an animal experiment. Spine 32: 1174-1180.

Halloran DO, Grad S, Stoddart M, et al. 2008; An injectable cross-linked scaffold for nucleus pulposus regeneration. Biomaterials 29: 438-447.

Hegewald AA, Ringe J, Sittinger M, et al. 2008; Regenerative treatment strategies in spinal surgery. Front. Biosci. 13: 1507-1525.

Helen W, Gough JE. 2007; Cell viability, proliferation and extracellular matrix production of human annulus fibrosus cells cultured within PDLLA/Bioglass ${ }^{\circledR}$ composite foam scaffolds in vitro. Acta Biomater. 4: 230-243.

Johnson WEB, Eisenstein SM, Roberts S 2001; Cell cluster formation in degenerate lumbar intervertebral discs is associated with increased disc cell proliferation. Connect. Tissue Res. 42: 197-207.

Joung YK, Bae JW, Park KD. 2008; Controlled release of heparin-binding growth factors using heparin-containing particulate systems for tissue regeneration. Expert Opin. Drug Deliv. 5: 1173-1184.

Kalson N, Richardson S, Hoyland J. 2008; Strategies for regeneration of the intervertebral disc. Regen. Med. 3: 717-729.

Kandel R, Roberts S, Urban JPG. 2008; Tissue engineering and the intervertebral disc: the challenges. Eur. Spine J. 17: 480-491.

Khetan S, Burdick JA. 2010; Patterning network structure to spatially control cellular remodeling and stem cell fate within 3-dimensional hydrogels. Biomaterials $\mathbf{3 1}$ 8228-8234.

Kong MH, Do DH, Miyazaki M, et al. 2008; Rabbit model for in vivo study of intervertebral disc degeneration and regeneration. J Korean Neurosurg Soc 44: 327-333.

Lotz JC, Hsieh AH, Walsh AL, et al. 2002; Mechanobiology of the intervertebral disc. Biochem. Soc. Trans. 30: 853-858.

Luoma K, Riihimaki H, Luukkonen R, et al. 2000 Low Back Pain in Relation to Lumbar Disc Degeneration. Spine 25: 487-492.

Le Maitre C, Freemont A, Hoyland J. 2007; Accelerated cellular senescence in degenerate intervertebral discs: a possible role in the pathogenesis of intervertebral disc degeneration. Arthritis Res. Ther. 9: 45.

Li J, Zhu B, Shao Y, et al. 2009; Construction of anticoagulant poly (lactic acid) films via surface covalent graft of heparincarrying microcapsules. Colloids Surf. B Biointerfaces 70: 15-19.

Masuda K, Oegema TR Jr, An HS. 2004; Growth factors and the intervertebral disc. Spine 4: 330-340.

Mizuno H, Roy AK, Vacanti CA, et al. 2004; Tissue-engineered composites of anulus fibrosus and nucleus pulposus for intervertebral disc replacement. Spine 29: 1290-1297.

Hamilton DJ, Séguin CA, Wang J, et al. 2005; Formation of a nucleus pulposus-cartilage endplate construct in vitro. Biomaterials 27: 397-405.

Merceron C, Vinatier C, Clouet J, et al. 2008; Adipose-derived mesenchymal stem cells and biomaterials for cartilage tissue engineering. Joint Bone Spine 75: 672-674.
Masuda K, Takegami K, An H, et al. 2003; Recombinant osteogenic protein-1 upregulates extracellular matrix metabolism by rabbit annulus fibrosus and nucleus pulposus cells cultured in alginate beads. $J$. Orthop. Res. 21: 922-930.

Macri L, Silverstein D, Clark RAF. 2007; Growth factor binding to the pericellular matrix and its importance in tissue engineering. Adv. Drug Deliv. Rev. 59: 1366-1381.

Moon SH, Nishida K, Gilbertson LG, et al. 2008; Biologic Response of Human Intervertebral Disc Cells to Gene Therapy Cocktail. Spine 33: 1850-1855.

Mizuno H, Roy AK, Zaporojan V, et al. 2006; Biomechanical and biochemical characterization of composite tissue-engineered intervertebral discs. Biomaterials 27: 362-370.

Nerurkar NL, Elliott DM, Mauck RL. 2010 Mechanical design criteria for intervertebral disc tissue engineering. J. Biomech 43: 1017-1030.

Nachemson AL, Evans JH. 1968; Some mechanical properties of the third human lumbar interlaminar ligament (ligamentum flavum). J. Biomech. 1: 211-220.

Nagae M, Ikeda T, Mikami Y, et al. 2007; Intervertebral disc regeneration using platelet-rich plasma and biodegradable gelatin hydrogel microspheres. Tissue Engineering 213: 147-158.

Nerurkar NL, Elliott DM, Mauck RL. 2007; Mechanics of oriented electrospun nanofibrous scaffolds for annulus fibrosus tissue engineering. J. Orthop. Res. 25: 1018-1028.

Nerurkar NL, Orlansky AS, Sen S, et al. 2008a; Multiscale tissue engineering of the intervertebral disc. Transactions of the 54th Annual Meeting of the Orthopaedic Research Society, San Francisco, CA, 0349; March, 2-5. (oral communication)

Nesti LJ, Li WJ, Shanti RM, et al. 2008; Intervertebral disc tissue engineering using a novel hyaluronic acid-nanofibrous scaffold (HANFS) amalgam. Tissue Eng. Part A 14 1527-1537.

Nerurkar NL, Mauck RL, Elliott DM. 2008b ISSLS prize winner: Integrating theoretica and experimental methods for functional tissue engineering of the annulus fibrosus. Spine 33: 2691-2701.

Nerurkar NL, Baker BM, Sen S, et al. 2009, Nanofibrous biologic laminates replicate the form and function of the annulus fibrosus. Nature Mater 8: 986-992.

Nishida K, Kang JD, Gilbertson LG, et al. 1999; Modulation of the biologic activity of the rabbit intervertebral disc by gene therapy: an in vivo study of adenovirusmediated transfer of the human transforming growth factor beta 1 encoding gene. Spine 24: 419-2425.

Nie H, Wang CH. 2007; Fabrication and characterization of PLGA/HAp composite scaffolds for delivery of BMP-2 plasmid DNA. J. Control. Release 120: 111-121.

Oliveira JT, Santos TC, Martins L. 2010 Gellan gum injectable hydrogels for cartilage tissue engineering applications: In vitro studies and preliminary in vivo evaluation. Tissue Eng. Part A 16: 343-353.

Oliveira JT, Martins L, Picciochi R et al. 2009a; Gellan gum: A new biomaterial for cartilage tissue engineering applications. J. Biomed. Mater. Res. A 93 852-863.

Oliveira JT, Santos TC, Martins L, et al 2009b; Performance of new gellan gum hydrogels combined with human articular chondrocytes for cartilage regeneration when subcutaneously implanted in nude mice. J. Tissue Eng. Regen. Med. 3: 493-500.

Pereira DR, Silva-Correia J, Caridade SG, et al. 2011; Development of Gellan-gum based microparticles/hydrogel matrices for application in the intervertebral disc regeneration. Tissue Eng Part C: Method 17: 961-972.

Pye SR, Reid DM, Lunt M, et al. 2007; Lumbar disc degeneration: association between osteophytes, end-plate sclerosis and disc space narrowing. Ann. Rheum. Dis. 66: 330-333.

Roberts S, Menage J, Urban JPG. 1989 Biochemical and structural properties of the cartilage end-plate and its relation to the intervertebral disc. Spine 14: 166-174.

Roberts S, Evans E, Kletsas D. 2006a; Senescence in human intervertebral discs. Eur. Spine J. 15: 312-316.

Richardson SM, Walker RV, Parker S, et al. 2006; Intervertebral disc cell-mediated mesenchymal stem cell differentiation. Stem Cells 24: 707-716.

Risbud MV, Albert TJ, Guttapalli A, et al. 2004; Differentiation of mesenchymal stem cells towards a nucleus pulposus-like phenotype in vitro: implications for cellbased transplantation therapy. Spine 29: 2627-2632.

Roughley PJ. 2004; Biology of intervertebral disc aging and degeneration: involvement of the extracellular matrix. Spine 29: 2691-2699.

Roberts S, Evans H, Trivedi J, et al. 2006b; Histology and pathology of the human intervertebral disc. J Bone Joint Surg Am 88: 10-14.

Richardson SM, Mobasheri A, Freemont AJ, et al. 2007; Intervertebral disc biology, degeneration and novel tissue engineering and regenerative medicine therapies. Histol. Histopathol. 22: 1033-1041.

Reza AT, Nicoll SB. 2010; Characterization of novel photocrosslinked carboxymethylcellulose hydrogels for encapsulation of nucleus pulposus cells. Acta Biomater. 6: 179-186.

Richardson SM, Hughes N, Hunt JA. 2008 Human mesenchymal stem cell differentiation to NP-like cells in chitosan-glycerophosphate hydrogels. Biomaterials 29: 85-93.

Roughley P, Hoemann C, DesRosiers E, et al. 2006; The potential of chitosan-based gels containing intervertebral disc cells for nucleus pulposus supplementation. Biomaterials 27: 388-396.

Reza A, Nicoll S. 2008; Hydrostatic pressure differentially regulates outer and inner annulus fibrosus cell matrix production in 3D scaffolds. Ann. Biomed. Eng. 36: 204-213.

Shankar H, Scarlett JA, Abram SE. 2009; Anatomy and pathophysiology of intervertebral disc disease. Tech Reg Anesth Pain Manag 13: 67-75.

Singh K, Masuda K, Thonar EJ, et al. 2009; Age-related changes in the extracellular matrix of nucleus pulposus and anulus fibrosus of human intervertebral Disc. Spine 34: 10-16. 
Sambrook PN, MacGregor AJ, Spector TD. 1999; Genetic influences on cervical and lumbar disc degeneration: a magnetic resonance imaging study in twins. Arthritis Rheum. 42: 366-372.

Schneider P, Oyen G. 1974a; Intervertebral disc replacement, experimental studies, clinical consequences. Z. Orthop. Ihre Grenzgeb. 112:791-792.

Slaughter BV, Khurshid SS, Fisher OZ, et al. 2009; Hydrogels in regenerative medicine. Adv. Mater. 21: 3307-3329.

Schneider P, Oyen G. 1974b; Plastic surgery on intervertebral disc: Part I intervertebral disc replacement in the lumbar regions with silicone rubber. Theoretical and experimental studies. Z. Orthop. Ihre Grenzgeb. 112: 1078-1086.

Silva-Correia J, Oliveira JM, Caridade SG, et al. 2010a; Gellan gum-based hydrogels for intervertebral disc tissue engineering applications. J. Tissue Eng. Regen. Med. (ahead of print).

Sakai D, Mochida J, Yamamoto Y, et al. 2003; Transplantation of mesenchymal stem cells embedded in Atelocollagen ${ }^{\circledR}$ gel to the intervertebral disc: a potential therapeutic model for disc degeneration. Biomaterials 24: 3531-3541.

Sawamura K, Ikeda T, Nagae M, et al. 2009; Characterization of in vivo effects of platelet-rich plasma and biodegradable gelatin hydrogel microspheres on degenerated intervertebral discs. Tissue Eng. Part A 15: 3719-3727.

Sakai D. 2008; Future perspectives of cellbased therapy for intervertebral disc disease. Eur. Spine J. 17: 452-458.

Sobajima S, Vadala G, Shimer A, et al. 2008; Feasibility of stem cell therapy for intervertebral disc degeneration. Spine J. 8: 888-896.

Silva-Correia J, Oliveira JM, Oliveira JT, et al. 2010b; Photo-crosslinked Gellangum based hydrogels: methods and uses thereof. WIPO submitted (Priority date: March 2010).

Seguin CA, Grynpas MD, Pilliar RM, et al. 2004; Tissue engineered nucleus pulposus tissue formed on a porous calcium polyphosphate substrate. Spine 29: 1299-1306.
Setton LA, Bonassar LJ, Masuda K, et al. 2007; Regeneration and replacement of the intervertebral disc. Principles of Tissue Engineering (3rd Edition). Burlington, p. 877-896.

Sato M, Asazuma T, Ishihara M, et al. 2003 An atelocollagen honeycomb-shaped scaffold with a membrane seal (ACHMS-scaffold) for the culture of annulus fibrosus cells from an intervertebral disc. J. Biomed. Mater. Res. A 64: 248-256.

Shao X, Hunter CJ. 2007; Developing an alginate/chitosan hybrid fiber scaffold for annulus fibrosus cells. J. Biomed. Mater. Res. A 82: 701-710.

Twomey L, Taylor J. 1985; Age changes in lumbar intervertebral discs. Acta Orthop. Scand. 56: 496-499.

Takegami K, An HS, Kumano F, et al. 2005; Osteogenic protein-1 is most effective in stimulating nucleus pulposus and annulus fibrosus cells to repair their matrix after chondroitinase $\mathrm{ABC}$-induced in vitro chemonucleolysis. Spine J. 5: 231-238.

Trout JJ, Buckwalter JA, Moore KC. 1982; Ultrastructure of the human intervertebral disc: II. Cells of the nucleus pulposus. Anat. Rec. 204: 307-314.

Vernengo J, Fussell GW, Smith NG, et al. 2008; Evaluation of novel injectable hydrogels for nucleus pulposus replacement. J. Biomed. Mater. Res. B Appl. Biomater. 84: 64-69.

Vinatier C, Mrugala D, Jorgensen C, et al. 2009; Cartilage engineering: a crucial combination of cells, biomaterials and biofactors. Trends Biotechnol. 27: 307-314.

Vadalà G, Studer RK, Sowa G, et al. 2008; Coculture of bone marrow mesenchymal stem cells and nucleus pulposus cells modulate gene expression profile without cell fusion. Spine 33: 870-876.

Vinatier C, Magne D, Weiss P, et al. 2005; A silanized hydroxypropyl methylcellulose hydrogel for the three-dimensional culture of chondrocytes. Biomaterials 26: 6643-6651.

Weishaupt D, Zanetti M, Hodler $\mathrm{J}$, et al. 2001; Painful lumbar disk derangement: relevance of endplate abnormalities at MR imaging1. Radiology 218: 420-427.
Wan Y, Feng G, Shen FH, et al. 2008; Biphasic scaffold for annulus fibrosus tissue regeneration. Biomaterials 29: 643-652.

Woods BI, Sowa G, Vo N, et al. 2010; A Change in strategy: the use of regenerative medicine and tissue engineering to augment the course of intervertebral disc degeneration. Oper Tech Orthop 20: 144-153.

Waldman SD, Grynpas MD, Pilliar RM, et al. 2002; Characterization of cartilagenous tissue formed on calcium polyphosphate substrates in vitro. J. Biomed. Mater. Res. 62: 323-330.

Walker MH, Anderson DG. 2004; Molecular basis of intervertebral disc degeneration. Spine J. 4: 158-166.

Wan Y, Feng G, Shen FH, et al. 2007; Novel biodegradable poly(1,8-octanediol malate) for annulus fibrosus regeneration. Macromol. Biosci. 7: 1217-1224.

Wang C, Gong Y, Lin Y, et al. 2008; A novel gellan gel-based microcarrier for anchorage-dependent cell delivery. Acta Biomater. 4: 1226-1234.

Wilke HJ, Heuer F, Neidlinger-Wilke C, et al. 2006; Is a collagen scaffold for a tissue engineered nucleus replacement capable of restoring disc height and stability in an animal model? Eur. Spine $J$. 15: 433-438.

Wallach CJ, Sobajima S, Watanabe Y, et al. 2003; Gene transfer of the catabolic inhibitor TIMP-1 increases measured proteoglycans in cells from degenerated human intervertebral discs. Spine $\mathbf{2 8}$ 2331-2337.

Yeung AT, Yeung CA. 2007; Minimally invasive techniques for the management of lumbar disc herniation. Orthop. Clin. North Am. 38: 363-372.

Yang X, Li X. 2009; Nucleus pulposus tissue engineering: a brief review. Eur. Spine J. 18: $1564-1572$

Zhang Y, Anderson DG, Phillips FM, et al. 2007; Comparative effects of bone morphogenetic proteins and Sox9 overexpression on matrix accumulation by bovine anulus fibrosus cells - implications for anular repair. Spine 32: 2515:2520. 